\title{
TTG MESIN PENGHALUS PIPA ROLL CONVEYOR PENGGANTI MESIN BUBUT WILAYAH SURABAYA BARAT
}

\author{
Mochammad Muchid, Subaderiं ${ }^{2}$, Dwi Yustianto ${ }^{3}$, Andianto Wahyu Nugroho ${ }^{4}$ \\ ${ }^{1}$ Universitas Wijaya Putra Fakultas Teknik Mochammad Muchid \\ ${ }^{2}$ Universitas Wijaya Putra Fakultas Teknik Subaderi \\ ${ }^{3}$ Universitas Wijaya Putra Fakultas Teknik Dwi Yustianto \\ ${ }^{4}$ Universitas Wijaya Putra Fakultas Teknik Andianto Wahyu Nugroho
}

muchid@uwp.ac.id, subaderi@pal.co.id,dwiyustiant@gmail.com, andianto1903@gmail.com

\begin{abstract}
Abstrak
Teknologi Tepat Guna mesin penghalus roll conveyor berada di Wilayah Surabaya Barat, tepatnya di Desa Kandangan Kecamatan Benowo. Mortek Suraindo adalah workshop yang bergerak dibidang jasa dan pembuatan mesin asphalt sprayer, karoseri, silo, serta conveyor. Mortek Suraindo kegiatan yang sering dikerjakan adalah pembuatan roll conveyor, roll conveyor terdiri dari roll and bracket. Pelaksanaan pembuatan roll terdiri beberapa komponen yang digunakan yaitu: pipa, house bearing, bearing 6203, cover house bearing, snap ring and axle, produksi pembuatan roll ada beberapa komponen yang di jasakan di workshop lain dengan asumsi inventaris mesin dan waktu. Proses pekerjaan yang dikerjakan diluar membutuhkan mesin bubut untuk memotong dan meratakan hasil pengelasan antara pipe dengan house bearing, harga pekerjaan ini setiap $1 p c \mathrm{Rp}$. 7,000 setiap minggu mampu mengerjakan 200 pcs, harga jasa 1 bulan = Rp. 5,600.000 untuk memangkas pengeluaran maka tim PKM Universitas Wijaya Putra membuat prototype design mesin penghalus roll conveyor menggunakan software SolidWork, dengan tujuan memastikan kegagalan yang ada, dan dilanjutkan pembuatan mesin roll conveyor serta di sosialisaikan dan digunakan selama 10 bulan ini mampu mengerjakan $\pm 14,000$ pcs dan mampu memperoleh keuntungan Rp. 21,000,000 serta dapat membeli mesin penghalus roll conveyor
\end{abstract}

Kata Kunci : Mesin Bubut, Pkm, Prototype Design, Roll Conveyor, Solidwork

\section{PENDAHULUAN}

Perkembangan zaman yang disertai oleh perkembangan ilmu pengetahuan dan teknologi (IPTEK) yang pesat menciptakan era globalisasi dan keterbukaan bagi setiap individu untuk ikut serta di dalamnya, sehinggga sumber daya manusia harus menguasai IPTEK serta mampu mengaplikasikannya dalam setiap kehidupan.

Bidang rekayasa teknik mesin ada sebuah praktek kerja yang melibatkan keahlian dalam bidang Mechanical Engineering ,workshop Mortekh Suraindo semua kegiatan berkaitan dengan proyek lama dan baru harus dilakukan analisa dengan menggunakan Computer Aided Design terlebih dahulu untuk menciptakan pemodelan mesin, analisa kegagalan produk baik benturan, dimension, bill of material dan coasting produk dengan memperhatikan kualitas produk yang berpengaruh terhadap jasa pembuatan dan penjualan produk. Untuk menjalankan aktivitas, Mortekh Suraindo terkendala dengan keuangan untuk pengadaan mesin, untuk menyiasati dengan pengadaan mesin maka perlu dilakukan investasi mesin penghalus roll conveyor dengan harga minimal tetapi fungsinya sama dengan mesin yang dibutuhkan. Mesin roll conveyor ini dibuat sebagai pengganti mesin bubut yang bertujuan untuk memotong serta

$$
\text { Teknologi Tepat Guna }
$$


meratakan bagian pipa yang di las dengan house bearing dan mesin roll conveyor ini tidak diciptakan sepenuhnya sebagai mesin bubut melainkan mengambil salah satu fungsi dari mesin bubut. Mesin roll conveyor ini dilengkapi dengan gerinda tangan yang didesain sedemikian rupa dibantu dengan dua buah linear bearing yang dipasang secara vertikal dan horizontal, serta dipasang $f y h$ bearing, sehingga gerinda tangan dapat digerakan secara bebas baik horizontal dan vertical

Pekerjaan jasa yang dilakukan untuk membersihkan hasil sisa pengelasan apabila dijasakan ditempat lain Rp. 7,000/pc dan setiap minggunya mampu mengerjakan 200 pcs harga perbulannya Rp. 5,600,000

\section{METODE}

\section{Roll Conveyor}

Berikut ini gambar 3D Assembly roll conveyor

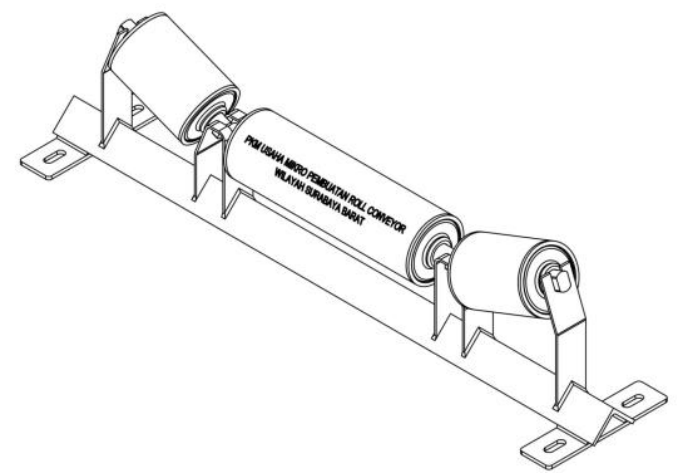

Gambar 1. (Roll conveyor)

Roll conveyor ini terdiri dari beberapa komponen part yaitu: pipa, house bearing, bearing, snap ring, axle

Proses awal pekerjaan roll conveyor adalah dengan membuat 3D produk dengan bantuan Computer Aided Design baik komponen dan mengabungkan beberapa komponen kemudian dilihat secara benturan, dimensi kekuatan serta memberikan toleransi pada gambar dengan tujuan sebagai panduan gambar kerja serta pertanggung jawaban supplier didalam proses kerja. Berikut ini bill of material roll conveyor tanpa menggunakan bracket sebab bracket tidak menggunakan proses permesinan

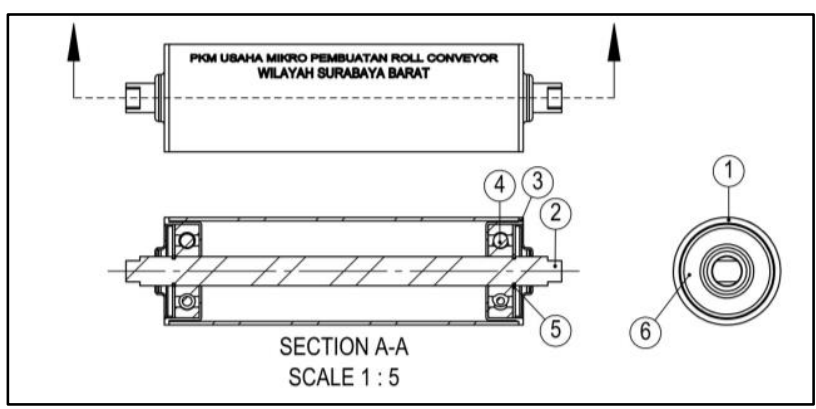

Gambar 2. (Bill of material conveyor)

Tabel 1. Bill of material roll conveyor

\begin{tabular}{llcc}
\hline NO & $\begin{array}{l}\text { Name } \\
\text { Komponen }\end{array}$ & Dimension & Qty \\
\hline 1 & Pipa & $\varnothing 101.6 \times 122$ & 2 \\
2 & As & $\varnothing 25 \times 180$ & 2 \\
3 & House bearing & $\varnothing 101.6 \times 32$ & 6 \\
4 & Bearing & Radial (Standart) & 6 \\
5 & Snap ring & (Standart) & 6 \\
6 & Cover house & $\varnothing 80 \times 15$ & 6 \\
& bearing & $\varnothing 101.6 \times 300$ & 1 \\
7 & Pipa & $\varnothing 25 \times 374$ & 1 \\
8 & As & (Standart) & 1 \\
9 & Bracket & & - \\
- & & & \\
\hline
\end{tabular}

dari data tabel diatas menegaskan bahwa item roll conveyor ada yang sama baik bentuk dan fungsinya ada juga yang berbeda secara dimensi lainnya, komponen yang sama misal: bearing, snap ring, cover house bearing.

\section{Pemotongan Pipa}

Pipa yang digunakan di dalam pembuatan roll conveyor ini menggunakan $\varnothing 90 \mathrm{~mm}$ tetapi berbeda panjang, untuk mempercepat proses tanpa mengukur berulang-ulang serta pemotongan lurus maka dibuatkan penahan (stoper) kemudian pipa ini harus dipotong lagi di mesin bubut dengan harapan rata serta pembentukan chamfer pada ke dua permukaan atas dan bawah yang berfungsi tempat pengelasan. Dalam proses ini sangat penting sebab akan dihubungkan dengan house bearing 
Berikut ini gambar sesudah pipa di proses di mesin bubut
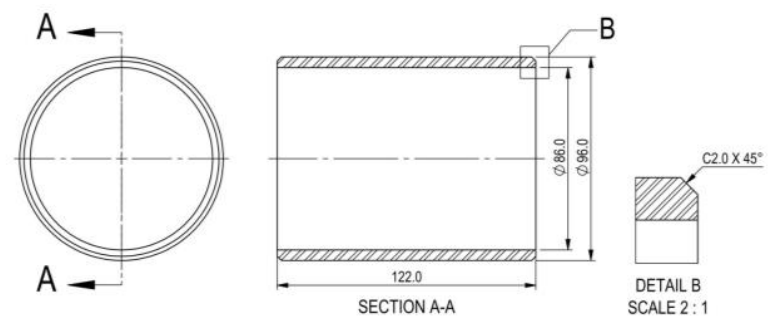

Gambar 3. (Proses perataan pipa dan pembuatan chamfer menggunakan mesin bubut)

\section{Pembuatan House Bearing}

House bearing ini seharusnya jadi satu dengan pipa tetapi harga dari customer tidak bersahabat bahkan sangat rendah maka desain pemodelan dari roll conveyor berubah yang di pengaruhui dari harga sebab kalau kita menggunakan pipa dengan secara utuh maka berat semakin bertambah, untuk menjalankan kinerja perekonomian yang ada maka design roll conveyor harus berubah untuk menurunkan harga (cost down), tetapi didalam tingkat keamanan masih terjaga dengan baik karena design berdasarkan FOS.

Pada bagian house bearing ini sangat diperhatikat tingkat ketelitiannya sebab berpasangan dengan bearing 6203, dan cover house bearing dalam proses ini harus diperhatikan juga apabila house bearing dan pipa dilakukan proses pengelasan akan menggalami perubahan material menjadi deformasi dan akan berpengaruh pada tempat bearing. Berikut ini gambar sebelum dan sesudah pipa di proses menjadi house bearing
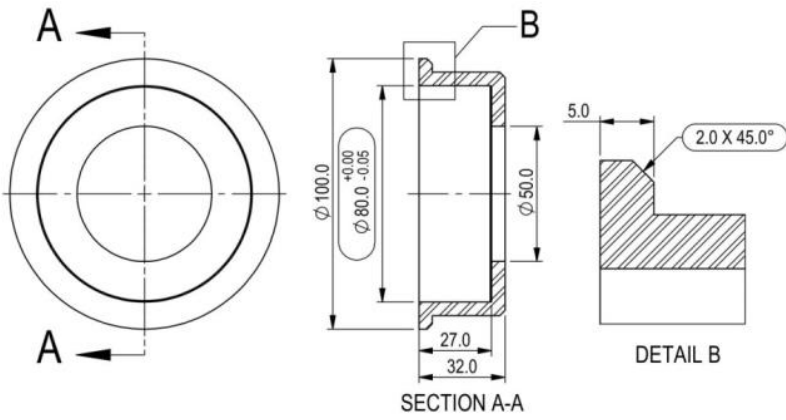

Gambar 4. (Proses pembuatan house bearing menggunakan mesin bubut)

\section{Pemotongan AS}

Prinsipnya hampir sama dengan proses pemotongan pipa yaitu dengan menggunakan cutting circle dan diberikan penahan (stoper) untuk mengukur panjang as tanpa berulang-ulang menentukan panjangnya, setelah as selesai di potong kemudian dilakukan proses mesin bubut untuk pembentukan cincin as yang digunakan tempat snap ring agar tidak dapat berpindah-pindah, setelah proses pembuatan rumah snap ring selesai maka dilanjutkan dengan membuat penahan (stoper) bracket kanan dan kiri dengan proses menggunakan mesin frais

\section{Pengelasan antara Pipa dan House Bearing}

Pada proses pengelasan antara pipa dan house bearing juga perlu di perhatikan didalam pemilihan electroda dan daya pengelasan serta teknik pengelasan sebab kalau salah pemilihan dan teknik akan menimbulkan deformasi yang akan berdampak kegagalan produk, material pipa akan berubah bentuk dan bearing tidak dapat dimasukan dan kalau dipaksa bearing tidak bisa berputar dengan baik secara fungsinya. Berikut ini gambar proses pengelasan antara pipa dan house bearing
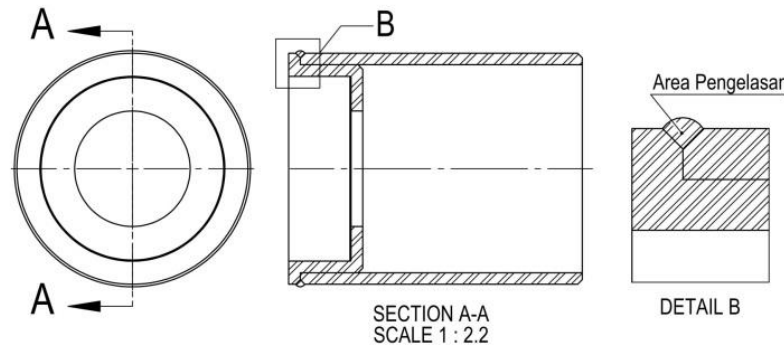

Gambar 5. (Proses pengelasan antara pipa dan house bearing)

\section{Pemotongan Sisa Pengelasan antara Pipa dengan House Bearing}

Perataan sisa pengelasan antara pipa dengan house bearing menggunakan proses permesinan mesin bubut, proses ini untuk memotong sisa pengelasan menjadi halus atau memberikan radius dan membersihkan percikan-percikan pengelasan yang mengenai pipa. Untuk proses penelitian dan

$$
\text { Teknologi Tepat Guna }
$$


pengabdian proses pemotongan sisa pengelasan antara pipa dengan house bearing menjadi tolak ukur didalam perhitungan pembuatan mesin data untuk proses ini dari jasa workshop yang lain adalah Rp. 7,000 / $p c$ dan proses pekerjaan ini lebih mudah dikerjakan sendiri dengan menggunakan alat bantu yang sudah ada tetapi sangat manual dan untuk keselamatan pekerja kurang terjaga sebab pelatakan kurang sesuai dengan regulasi standart bekerja. Berikut ini gambar sebelum dan sesudah proses perataan sisa pengelasan antara pipa dan house bearing
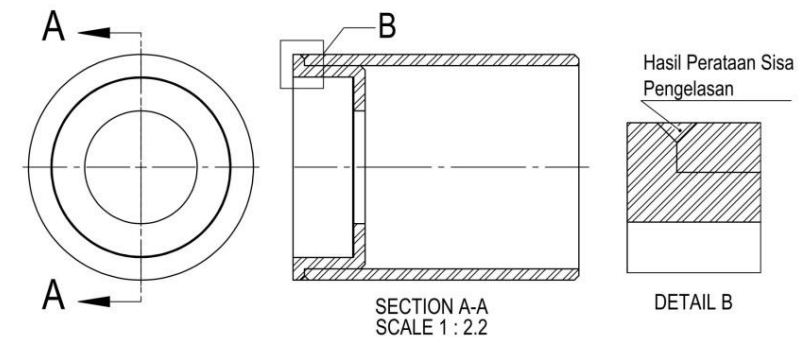

Gambar 6. (Proses sisa pengelasan antara pipa dengan house bearing)

\section{Proses Assembly}

Proses pemasangan semua komponen roll conveyor juga diperhatikan karena proses ini kita anggap proses finishing sebelum di painting, pemasangan bearing dengan pipa yang sudah disatukan dengan house bearing menggunakan peralatan seadaanya yaitu menggunakan palu karet, palu kuningan, tang snap ring dan pipa.

Pemasangan bearing dengan pipa yang sudah disatukan dengan hause bearing harus dibersihkan dulu untuk menghindari adanya sisa pengelasan berupa terak dan gram hasil permesinan mesin bubut yang kurang sempurna, kalau semua proses sudah dilakukan sesuai dengan standart, waktu pemasangan pipa yang sudah disatukan dengan house bearing diletakan diarea tanah yang flat atau datar permukaan tanah yang sudah diberikan plat diatasnya dimensi plat 300x300x10t pipa yang sudah disatukan dengan hause bearing menghadap vertikal kemudian buka bearing dari paking selanjutnya masukan ke house bearing dan berikan house bearing grase atau oil dan selanjutnya pukul dengan menggunakan palu karet secara berlahan-lahan sampai bearing itu masuk dalam keseluruhan dan gunakan pipa untuk meneruskan bearing masuk ke house bearing dengan tepat menempel pada permukaan bawah house bearing. lakukan pada bagian yang bawahnya juga dengan proses yang sama. Berikut ini gambar assembly roll conveyor
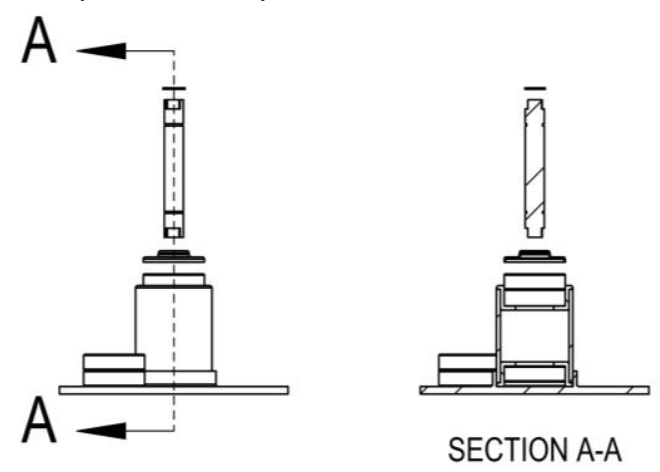

Gambar 7. (Proses assembly semua komponen roll conveyor)

\section{Proses Painting}

Proses painting pada roll conveyor ini adalah pekerjaan memberikan warna pada roll conveyor dengan warna hitam dan bracket dengan warna merah, proses painting yang dilakukan hanya bagian permukaan atasnya saja dan berikut ini gambar hasil painting

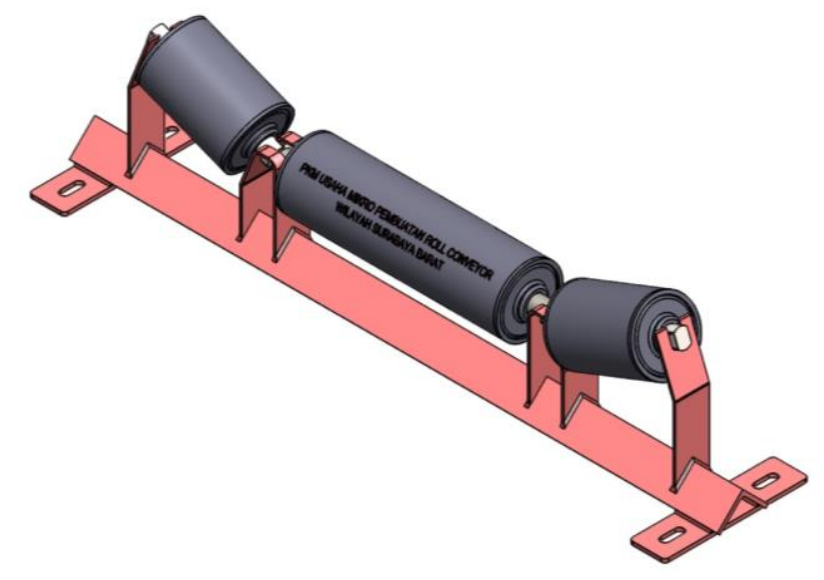

Gambar 8. (Proses painting roll conveyor dan bracket)

Proses painting ini tergaantung pada luas permukaan 


\section{HASIL DAN PEMBAHASAN}

\section{Analisa Status dan Banyaknya Hasil Pekerjaan}

conveyor

Berikut ini tabel proses pembuatan roll

Tabel 2. Proses pekerjaan roll conveyor

\begin{tabular}{clcc}
\hline No & \multicolumn{1}{c}{ Proses } & Status & $\begin{array}{c}\text { Pcs/evry } \\
\text { week }\end{array}$ \\
\hline 1 & $\begin{array}{l}\text { Pemotongan pipa } \\
\text { dan membuat } \\
\text { chamfer untuk } \\
\text { area pengelasan } \\
2\end{array}$ & Create & 400 \\
& $\begin{array}{l}\text { Pembuatan house } \\
\text { bearing }\end{array}$ & Jasa & 200 \\
3 & $\begin{array}{l}\text { Pemotongan as } \\
\text { dan pembuatan } \\
\text { rumah snap ring }\end{array}$ & $\begin{array}{l}\text { Create } \\
\text { \& jasa }\end{array}$ & 200 \\
4 & $\begin{array}{l}\text { Pengelasan antara } \\
\text { house bearing dan } \\
\text { pipa }\end{array}$ & Create \\
\hline 5 & $\begin{array}{l}\text { Perataan sisa } \\
\text { pengelasaan antara } \\
\text { house bearing dan } \\
\text { pipa } \\
\text { Assembly }\end{array}$ & Jasa & 150 \\
\hline 7 & Painting & Create \\
\hline
\end{tabular}

dari semua proses yang ada pada tabel pembuatan roll conveyor dapat diketahui bahwa pekerjaan dengan status jasa harus ditingkatkan lagi sebab tidak sebanding dengan pekerjaan yang dikerjakan sendiri ini dapat diketahui pada No. 3 dan 5 proses pemotongan as dan pembuatan rumah snap ring serta perataan sisa pengelasan antara house bearing dan pipa tidak seimbang perolehannya kalau jasa 200 dan 150 per minggunya sedangkan untuk part yang lainya sudah 400 pcs. Dengan tidak imbangnya pihak jasa melayani kebutuhan akan terjadinya telatnya kiriman dan penumpukan material dan mengakibatkan lahan semakin sempit yang fungsinya berubah hanya penyimpanan material, Sementara permintaan pembuatan roll conveyor semakin tinggi sebab perusahaan mampu mensupply ke 3 distributor yang ada pada Wilayah Surabaya. Maka dari itu tim pengabdian masyarakat
Universitas Wijaya Putra membuat mesin penghalus pipa roll conveyor sebagai pengganti mesin bubut

\section{Hasil Desain Mesin Penghalus Roll Conveyor Penghalus sebagai Pengganti Mesin Bubut}

Hasil desain mesin penghalus roll conveyor ini menggunakan CAD SolidWork yang mana bertujuan untuk memudahkan cara penggunaannya bagi operator yang menjalankannya serta terjamin keselamatannya, desain roll conveyor ini memiliki panjang 800, lebar 400 dan ketinggian 1000, berikut ini gambar mesin penghalus roll conveyor
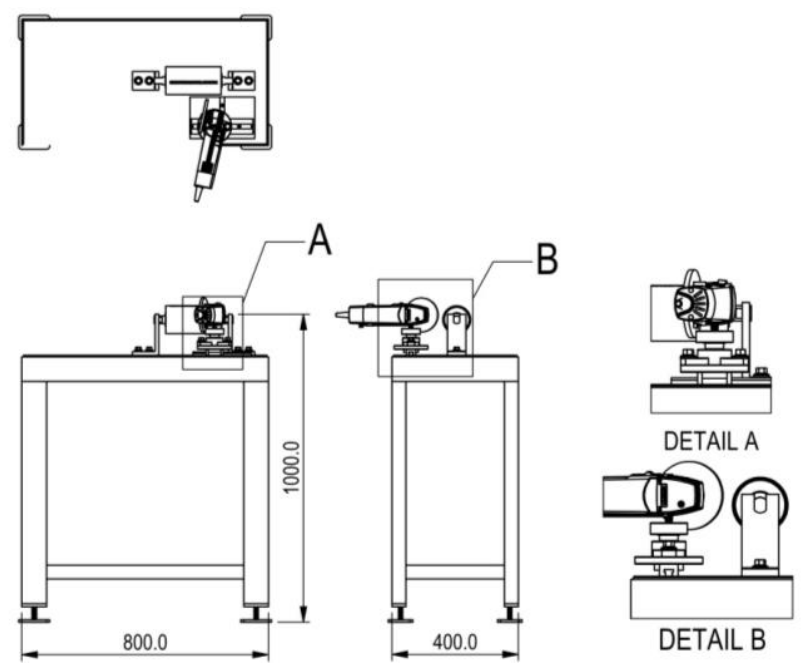

Gambar 9. (Desain mesin roll conveyor)

Mesin penghalus roll conveyor ini dilengkapi dengan gerinda tangan yang digunakan sebagai motor dan sekaligus pisau, serta memiliki penahan (stoper) sebagai tempat dudukan gerinda tangan dan dapat bergerak $360^{\circ}$ serta memiliki arah vertikal dan horizontal sebagai pengatur pergerakan gerinda tangan dan penahan roll yang digunakan untuk mengikat roll conveyor serta dapat dirubah panjang pendeknya sesuai kebutuhan.

Mesin penghalus roll conveyor ini menggunakan batu gerinda 4in dan 5in didalam penggunaannya dapat habis pakai dengan secara maksimal sebab dapat digerakan arah maju dan mundur 


\section{Hasil Pembuatan Mesin Penghalus Roll Conveyor Penghalus sebagai Pengganti Mesin Bubut}

Berikut ini hasil pembuatan roll conveyor yang dikerjakan di workshop Fio Jaya

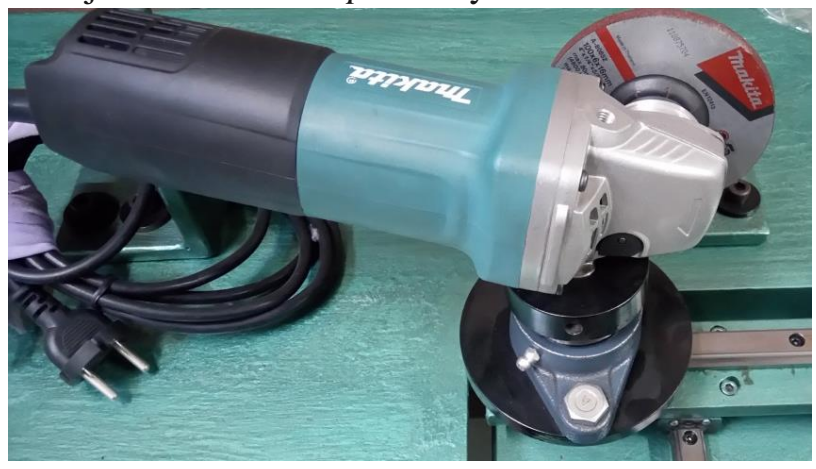

Gambar 10. (Hasil pembuatan mesin roll conveyor)

Hasil pembuatan mesin penghalus roll conveyor dibuat berdasarkan gambar yang dibuat oleh $\mathrm{MdP}$ Multiple design Product. Setelah desain dan pembuatan mesin penghalus roll conveyor sebagai pengganti mesin bubut sudah selesai dilanjutkan serah terima mesin ke mitra yang bersangkutan dan mengadakan pelatihan cara penggunaan mesin penghalus roll conveyor sebelum digunakan, setelah beberapa bulan kemudian pembuatan roll conveyor dapat meningkat dengan dijelaskan data tabel berikut ini

Tabel 3. Proses pekerjaan setelah pembuatan mesin roll conveyor digunakan

\begin{tabular}{clcc}
\hline No & \multicolumn{1}{c}{ Proses } & Status & $\begin{array}{c}\text { Pcs/evry } \\
\text { week }\end{array}$ \\
\hline 1 & $\begin{array}{l}\text { Pemotongan pipa } \\
\text { dan membuat } \\
\text { chamfer untuk } \\
\text { area pengelasan }\end{array}$ & Create & 400 \\
\hline 2 & $\begin{array}{l}\text { Pembuatan house } \\
\text { bearing }\end{array}$ & Jasa & 300 \\
3 & $\begin{array}{l}\text { Pemotongan as } \\
\text { dan pembuatan } \\
\text { rumah snap ring }\end{array}$ & $\begin{array}{l}\text { Create } \\
\text { \& jasa }\end{array}$ & 400 \\
\hline 4 & $\begin{array}{l}\text { Pengelasan antara } \\
\text { house bearing dan } \\
\text { pipa }\end{array}$ & Create \\
\hline 5 & $\begin{array}{l}\text { Pemotongan sisa } \\
\text { pengelasaan antara }\end{array}$ & Create & 380 \\
\hline
\end{tabular}

\begin{tabular}{llll}
\hline \multicolumn{3}{|c}{$\begin{array}{l}\text { house bearing dan } \\
\text { pipa }\end{array}$} & \\
\hline 6 & Assembly & Create & 400 \\
7 & Painting & Create & 400 \\
\hline
\end{tabular}

Setelah melihat data yang sudah ada bahwasaanya kegiatan pembuatan mesin penghalus roll conveyor sangat membantu didalam pembuatan roll conveyor dari perataan sisa pengelasan naik menjadi 380 pcs awalnya 150 pcs dan diimbangi pula naiknya assembly part dan painting sama naik menjadi 400 pcs sehingga Pengabdian Kepada Masyarakat yang dilakukan oleh tim Universitas Wijaya Putra telah berhasil menggangkat finansial mitra

\section{KESIMPULAN}

Setelah melakukan kegiatan ini status jasa yang dikerjakan oleh permesinan mesin bubut lebih cepat dari mesin penghalus roll conveyor. pembuatan mesin penghalus roll conveyor ini mempengaruhui kenaikan pada proses assembly, dan painting

\section{UCAPAN TERIMA KASIH}

Ucapan terima kasih juga kami sampaikan kepada Bapak Rektor, ketua LPPM dan Dekan Teknik Universitas Wijaya Putra yang banyak memberikan dorongan dan masukan sekaligus melakukan monitoring pelaksanaan kegiatan ini.

\section{REFERENSI}

[1] Alspaugh, Mark, 2008, Bulk Material Handling by Conveyor Belt, Society for Mining, Metallurgy, Exploration. Inc, Colorado, USA

[2]Arief, Syafri, 2017, Perancangan Bark Belt Conveyor 27b Kapasitas 244 Ton/Jam, Universitas Riau, Pekanbaru

[3]Conveyor Belt Technique-Design and Calculation, Dunlop, 2011, Australia.

[4] Conveyor Equipment Manufacturer Association (CEMA), 2002, Belt Conveyor for Bulk Material, US

[5] Erinofiardi. 2010. Perancangan dan daya motor belt conveyor 30 Ton/jam. Teknomekanik Vol. 2,

Teknologi Tepat Guna 
No. 2, hlm:164-175, universitas bengkulu, bengkulu..

[6] Erinofiardi. 2012. Analisa Kerja Belt Conveyor 5857-V Kapasitas 600 Ton/Jam. Jurnal Rekayasa Mesin Vol. 3, No. 3, ISSN: 0216-468X, universitas bengkulu, bengkulu

[7] Jagtap A A, Vaidya S D, Samrutwar A R, Kamadi R G and Bhende N V. 2015. Design Of Material Handling Equipment: Belt Conveyor System For Crushed Biomass Wood Using V Merge

Conveying System. International Journal of Mechanical Engineering and Robotics Research. Department of Mechanical Engineering, $J \quad D$ College of Engineering \& Management, Nagpur, India.

[8] Spot, MF, 1985, Machine Element, Printice Hall of India Privated Limited.

[9] Sularso, 1987, Dasar Perancangan dan Pemilihan Elemen Mesin, PT.Pradnya Paramita, Jakarta.

[10]Zainuri, ST. Muhib, 2006, Mesin Pemindah Bahan (Material Handling Equipment), Penerbit Andi, Jogjakarta. 